\title{
A influência de noções e valores do campo do design nas práticas e discursos relacionados à criação e desenvolvimento de objetos do vestuário vinculados à noção de moda
}

The influence of notions and values of the design field on practices and discourses related to the creation and development of clothing objects linked to the notion of fashion

CHRISTO, Deborah Chagas; Doutora em Design; PUC-Rio

deborahchristo@gmail.com

SABRÁ, Flávio Glória Caminada; Doutor em Design; IFRJ - Campus Belford Roxo

flaviosabra@gmail.com

\section{Resumo}

Este artigo apresenta uma análise sobre a influência das noções, valores e práticas do campo tradicional do design nas práticas e discursos relacionados à criação e desenvolvimento de objetos do vestuário vinculados à noção de moda. Esta análise é o início de uma pesquisa sobre como estas noções e valores foram apropriados e interpretados pelas instituições de ensino de design e de moda localizadas no Rio de Janeiro, após a adequação, sugerida pelo MEC, dos projetos pedagógicos de cursos de nível superior de moda e estilismo às Diretrizes Curriculares Nacionais do Curso de Graduação em Design, em 2004, e como isso afetou efetivamente as práticas de ensino relacionadas à criação e desenvolvimento do objeto do vestuário vinculado à noção de moda a partir de então.

Palavras Chave: campo do design; campo do design de moda; noções e valores.

\begin{abstract}
This article presents an analysis of the influence of the notions, values and practices of the traditional field of design in the practices and discourses related to the creation and development of clothing objects linked to the notion of fashion. This analysis is the beginning of a research on how these notions and values were appropriated and interpreted by the design and fashion teaching institutions located in Rio de Janeiro, after the adaptation, suggested by the MEC, of the pedagogical projects of higher education courses. fashion and styling to the National Curriculum Guidelines of the Design Graduation Course in 2004, and how this effectively affected teaching practices related to the creation and development of the clothing object bound to the notion of fashion from then on.
\end{abstract}

Keywords: design field; fashion design field; notions and values. 


\section{A questão inicial: Moda é, ou não é, Design?}

Mesmo que seja aparentemente clara a relação entre o desenvolvimento de um objeto do vestuário vinculado à noção de moda e qualquer outro objeto pertencente tradicionalmente ao campo de atuação do designer, a adequação, por indicação do MEC (Ministério da Educação), dos projetos pedagógicos dos cursos de nível superior de Estilismo e de Moda às Diretrizes Curriculares Nacionais do Curso de Graduação em Design, gerou movimentos, não necessariamente explícitos, tanto de aceitação e aprovação, como de conflito e, até mesmo, em alguns casos, de rejeição, tanto por parte dos profissionais responsáveis pela criação e desenvolvimento de objetos do vestuário vinculados à noção de moda, como pelos profissionais consagrados como tradicionalmente pertencentes ao campo do design. As noções que permeiam os dois campos, e que de certa forma aproximaram os dois campos, também interferiram, e ainda interferem, na compreensão, assimilação e aceitação desta incorporação, tanto pelos produtores tradicionalmente entendidos como pertencentes ao campo do design, como pelos produtores de objetos do vestuário vinculados à noção de moda. Essa dificuldade de aceitação e assimilação pode ser percebida em diferentes instâncias, porém em instituições de reprodução como as escolas responsáveis pela formação de designers de moda, ou mesmo em escolas onde a formação em design inclui a moda como parte das suas habilitações, muitas vezes, isto fica mais perceptível, principalmente em disciplinas que tratam dos discursos, técnicas e práticas entendidas como específicas do design, como, por exemplo, as disciplinas que tratam das teorias, práticas, discursos, nomenclaturas e metodologias específicas do desenvolvimento de projetos de design.

\section{A transição do estilismo para o design de moda}

Em 2004, por indicação do MEC (Ministério da Educação), os cursos de nível superior de Estilismo e de Moda começaram a adequar seus projetos pedagógicos às Diretrizes Curriculares Nacionais do Curso de Graduação em Design ${ }^{1}$ (PIRES, 2007: 10-11), alterando, ou não, seus nomes para cursos de Design de Moda ${ }^{2}$. Mesmo considerando os vários questionamentos, conflitos e dissidências provocados por esta decisão, ela institucionalizou, a partir de então, a noção de que a criação e o desenvolvimento de objetos do vestuário vinculados à noção de moda no Brasil passavam a ser considerados como uma prática pertencente ao campo do design. Vale ressaltar que, no Brasil, a constituição e estruturação do campo do design recebeu forte influência de uma tradição modernista que valorizava a racionalização dos processos de criação e desenvolvimento, tanto de objetos artísticos como de objetos vinculados à produção industrial. Desta forma, acreditava-se que o objeto tido como objeto de design era fruto de uma prática resultante de um planejamento racional focado nas necessidades práticas e objetivas dos seus usuários, ou seja, a atividade do designer era entendida como o desenvolvimento de um projeto capaz de encontrar

\footnotetext{
${ }^{1}$ Na Resolução no 5, de 08 de março de 2004, foram aprovadas pela Câmara de Educação Superior do Conselho Nacional de Educação as diretrizes curriculares nacionais do curso de graduação em Design, estabelecendo os elementos estruturais mínimos que devem compor o projeto pedagógico do curso.

${ }^{2} \mathrm{Na}$ Universidade Veiga de Almeida do Rio de Janeiro, por exemplo, apesar de o curso estar adequado às Diretrizes Curriculares Nacionais do Curso de Graduação em Design, ele está registrado no INEP (Instituto Nacional de Estudos e Pesquisas Educacionais Anísio Teixeira) sob o nome Bacharelado em Moda. (Ver INEP. Disponível em: http://emec.mec.gov.br/emec/consulta-cadastro/detalhamento/d96957f455f6405d14 c6542552b0f6eb/MTY1/9f1aa921d96ca1df24a34474cc171f61/NzU = . Acesso em 20 nov 2016.)
} 
soluções para demandas objetivas e diretas dos usuários, deixando para o segundo plano o que era entendido como demandas subjetivas e estéticas. Isto significa que as escolhas formais propostas pelo designer na criação de um objeto, mesmo as mais subjetivas, eram justificadas por argumentos aparentemente científicos vinculados a teorias sobre a percepção humana das formas, sobre os processos de comunicação através de imagens, sobre estudos antropométricos que influenciavam a relação do homem com o objeto, enfim, sobre teorias e métodos que buscavam identificar, sistematizar e categorizar em dados mensuráveis e controláveis as diferentes questões que podiam influenciar a relação entre sujeito e objeto. Demandas que pudessem remeter a escolhas individuais, abstratas e subjetivas, ou seja, que podiam fugir de um padrão mensurável, tinham um valor secundário no processo de criação do objeto pelo designer. Isto não significa que estes objetos estivessem isentos das escolhas formais individuais e subjetivas do designer, ou mesmo, das demandas individuais e subjetivas dos usuários, mas que as questões mensuráveis e controláveis tinham maior valor e peso e constituíam os discursos próprios do campo na década de 1960, e mesmo posterior à década de 1960, tendo em vista que esta é uma noção que influenciou a constituição do campo, mas ainda influencia os valores próprios do campo e, consequentemente, seus discursos e práticas. ${ }^{3}$ Desta forma, mesmo que seja possível identificar, por exemplo, nos objetos desenvolvidos na época da institucionalização do campo do design, nas décadas de 1950 e 1960, marcas identitárias do estilo de determinado designer, ou mesmo a representação de valores e noções de determinados grupos sociais, ainda assim isto era, muitas vezes, camuflado por um discurso embasado em justificativas racionais e mensuráveis que buscavam eliminar os conteúdos estilísticos e individuais das escolhas formais que constituíam estes objetos e transformá-los em valores universais, atemporais e uniformes. Vale observar que a noção de que a razão e a ciência determinavam o processo de criação do designer era um valor, ou seja, era algo imaterial que garantia a legitimação da produção do designer e, não necessariamente, estava fundamentada em questões concretas e objetivas, mas em noções e valores próprios do campo. Era uma questão muito mais ideológica do que objetiva. Desta forma, a atividade do designer era legitimada dentro do campo a partir da noção de que ele era capaz de identificar um problema que atingia determinado grupo de usuários e propor, a partir de um estudo planejado, programado e sistematizado, uma solução para este problema materializada através de um objeto industrial. Por mais que estas fossem atividades que também permeassem as práticas dos designers, ou seja, que o designer efetivamente estudasse as necessidades dos usuários e, a partir de etapas sistematizadas e planejadas, propusesse soluções para problemas efetivamente identificados, ainda assim, estas atividades ganhavam um valor simbólico que diferenciava, legitimava e consagrava a produção do designer da de outros produtores que criassem e desenvolvessem objetos industriais. Neste sentido, na institucionalização do campo do design, projeto, usuário e função do objeto tinham teor ideológico e funcionavam como um valor específico e uma noção própria do campo. Neste momento, projeto era algo para além do planejamento das etapas de criação, desenvolvimento e produção do objeto, tinha técnicas, nomenclaturas e discursos próprios; usuário definia um grupo amplo desvinculado de questões de consumo e mercado e função do objeto era vinculada

\footnotetext{
${ }^{3}$ A análise sobre essas noções e valores próprios do campo de produção de objetos legitimados como design e sobre a institucionalização deste campo pode ser encontrada em CHRISTO, Deborah Chagas; CIPINIUK, Alberto. O campo do design e consagração das logomarcas: estudo da relação entre as instâncias de legitimação e consagração do campo do design e a linguagem gráfica das logomarcas produzidas nas décadas de 60 e 70 . Dissertação (Mestrado) Pontifícia Universidade Católica do Rio de Janeiro, Departamento de Artes e Design, 2003.
} 
principalmente a questões objetivas, práticas, concretas e capazes de serem medidas e controladas. Desta forma, no Brasil, na década de 1960 os objetos que valorizassem principalmente a questão da forma e do estilo, ou seja, que davam mais valor à noção de indivíduo, estilo e moda e não à noção de usuário, projeto e função como eram entendidos dentro do campo do design, não eram legitimados como pertencentes ao campo e não se enquadravam no campo de atuação de um designer. Neste sentido, naquele momento, a criação de objetos do vestuário vinculados à noção de moda não conseguia se enquadrar dentro das noções e valores próprios do campo do design, tendo em vista que a noção de moda valorizava, e ainda valoriza, a questão do novo, do autoral e das características individuais e subjetivas tanto do criador destes objetos, como dos usuários destes produtos. Além disso, o produto entendido como de moda, no momento da institucionalização do campo do design, estava vinculado a uma produção artesanal e autoral e não a uma produção em larga escala e industrial. Neste momento o produto entendido como moda era produzido artesanalmente e sob medida, inicialmente por ateliês e casas de moda que explicitamente produziam peças a partir de cópias de modelos comprados no exterior, ou de moldes adquiridos diretamente das maisons de alta-costura francesa ${ }^{4}$ e posteriormente por costureiros que faziam interpretações próprias a partir das formas consagradas pelos costureiros da alta-costura francesa legitimados pelo campo, seguindo seus lançamentos sazonais. O produto feito em larga escala em confecções industriais nesta época no Brasil era entendido como de menor qualidade e popular. A ideia de uma indústria da moda no Brasil só começou a se estabelecer a partir das décadas de 1980 e 1990. Segundo Bonadio, somente na década de 1980 o consumo preferencial de roupas feitas sob medida é substituído pelo consumo de objetos desenvolvidos em série seguindo medidas padrões. Até então, mesmo com o crescimento das confecções industriais e da valorização e inserção da noção de autoria dentro deste processo, o consumo de objetos do vestuário ainda era voltado, principalmente, para objetos produzidos artesanalmente e sob medida. (BONADIO, 2010: 57) Desta forma, tanto a valorização das características individuais e subjetivas do criador do objeto entendido como de moda e dos usuários destes produtos, como a produção artesanal e sob medida, não davam ao produto de moda, nem ao seu produtor, legitimidade para fazer parte do campo do design no momento da sua institucionalização.

Segundo Braga e Prado, no início da década de 1960 as confecções industriais brasileiras eram poucas e sem uma estrutura que privilegiasse uma produção entendida como autoral. Muitas empresas faziam altos investimentos em publicidade, porém sua produção era baseada na cópia de peças compradas no exterior, sem uma preocupação em estabelecer setores específicos para desenvolver uma criação de objetos de vestuário entendida como autoral. Porém, no final da década de 1970 e na década de 1980, já é possível considerar como consagrada esta categoria de produtores de objetos do vestuário em larga escala industrial, vinculados à noção de autoria. (BRAGA; PRADO, 2011: 368-377) Segundo Bonadio, na década de 1980, é possível identificar uma preocupação com a elaboração de um produto diferenciado e que retratasse uma identidade própria, mesmo que ainda seguisse as indicações formais dos produtores estrangeiros. (BONADIO, 2010: 57)

A partir da década de 1980, a produção de objetos do vestuário assume as características

\footnotetext{
${ }^{4}$ A partir de 1929, com o intuito de diminuir os impactos da crise econômica de 1929, as maisons de alta-costura francesa passaram a vender, além dos modelos, os moldes construídos em algodão, chamados de toiles, que serviam de base para a reprodução da peça comprada. (BRAGA; PRADO, 2011: 135-138)
} 
de uma produção em escala industrial visando o desenvolvimento de um produto diferenciado e com marcas de uma identidade própria, ou seja, a partir de então, passa a ter que incluir no seu processo de criação, além das escolhas estilísticas, autorais e individuais do criador, as demandas e requisitos dos consumidores, ou usuários, e das empresas produtoras destes objetos. Mesmo considerando a forte relação com a noção de autoria e assinatura do produto entendido como de moda, mesmo quando produzido em larga escala, ainda assim, é possível perceber que esta transformação no processo produtivo aproximou a percepção sobre a criação e desenvolvimento do objeto do vestuário, da criação e desenvolvimento dos objetos tradicionalmente entendidos como pertencentes ao campo do design.

Desta forma, a adequação dos cursos de Moda e Estilismo às Diretrizes Curriculares Nacionais do Curso de Graduação em Design, aparentemente marcou o final de um processo onde se identificava que a produção do objeto do vestuário vinculado à noção de moda possuía a mesma estrutura de criação e desenvolvimento de qualquer outro objeto de design. Um designer de moda, ou estilista, como qualquer outro designer, precisa ter conhecimento sobre os diversos fatores que podem interferir na configuração de um objeto, ou seja, ter conhecimento sobre as demandas subjetivas e objetivas dos usuários, os requisitos e restrições do produtor, a forma, os processos criativos, os materiais e processos de fabricação, os fatores que influenciam os custos de produção, etc.

\section{A influência da noção de moda no campo do design}

Por outro lado, no momento em que se considera que a busca por uma expressão própria e o interesse e gosto pelas mudanças podem ser demandas, mesmo que abstratas e subjetivas, dos usuários, novos requisitos também passam a orientar a criação e desenvolvimento dos objetos tradicionalmente pertencentes ao campo do design e, consequentemente, novos valores e noções passam a compor o campo do design, ou seja, quando o campo do design passa a considerar que o usuário tem necessidades e demandas subjetivas e simbólicas que podem gerar produtos materiais e imateriais que possuem, além de funções objetivas e práticas, funções simbólicas, as transformações formais sazonais, efêmeras e de curta duração, a valorização da novidade e a aparente possibilidade de expressão individual, valores claramente relacionados às noções características do fenômeno moda, passam a ser percebidas como fatores que interferem nas relações dos sujeitos com todos os tipos de objetos da cultura material na sociedade e como fator fundamental no funcionamento do mercado e na estrutura da produção industrial. Desta forma, talvez seja possível afirmar que a abrangência do fenômeno moda também tenha atingido o campo do design, interferindo nos seus valores e critérios, no seu funcionamento, nos seus agentes e nas características dos seus produtos, incentivando a aproximação entre o campo de produção de objetos do vestuário vinculados à noção de moda e o campo do design.

Talvez a necessidade de legitimação e profissionalização da indústria do vestuário possa ter contribuído para a aproximação do campo de produção de objetos do vestuário vinculados à noção de moda, das noções que aproximam o design da produção industrial. Mas, por outro lado, o desenvolvimento de uma sociedade voltada para um mercado que tem, muitas vezes, a possibilidade, ou a ideia de possibilidade, de uma inserção global onde a informação estaria ao alcance de qualquer um e a concorrência seria maior, também pode ter incentivado a necessidade de diferenciação e obsolescência do objeto, valorizando e legitimando o fenômeno moda como ferramenta estratégica para o êxito comercial de qualquer produto inserido no mercado, por ter como característica a valorização da autonomia do indivíduo e a busca constante pelo novo, 
aproximando as noções características do campo da moda das do campo do design. Com isso, talvez seja possível afirmar que a relação entre as noções associadas ao campo de produção de objetos do vestuário vinculados à noção de moda e as relacionadas ao campo de produção de objetos de design se alteraram, como também o valor dessas noções, dos produtores legitimados por elas e dos seus produtos, influenciando e alterando também a própria estrutura e o funcionamento dos dois campos e os aproximando.

\section{Análise da influência das noções e valores do campo do design nas práticas e discursos relacionados à criação e desenvolvimento dos objetos de moda}

Desta forma, é possível perceber que a noção de que a criação e o desenvolvimento de objetos do vestuário vinculados à noção de moda pertencem ao campo de produção de objetos de design e a sugestão de adequação dos projetos pedagógicos dos cursos superiores de estilismo e moda às Diretrizes Curriculares Nacionais do Curso de Graduação em Design foram resultado de um processo de transformação das noções e valores e da estrutura e funcionamento destes dois campos de produção, ou seja, que este foi um processo de mão dupla que conjugou os interesses e objetivos destes dois campos. ${ }^{5}$ Mesmo assim, apesar de parecer que este processo foi resultado de uma transição natural e esperada tanto dentro do campo de produção dos objetos do vestuário vinculados à noção de moda, como do campo de produção dos objetos de design, este não foi um movimento sem conflitos e reações. As noções que permeiam os dois campos, e que de certa forma aproximaram os dois campos, também interferiram, e ainda interferem, na compreensão, assimilação e aceitação desta incorporação, tanto pelos produtores tradicionalmente entendidos como pertencentes ao campo do design, como pelos produtores de objetos do vestuário vinculados à noção de moda. A noção que vincula o objeto do vestuário a um produto efêmero e marcado pela expressão autoral do seu criador e, consequentemente, o associa a um objeto fútil e desnecessário, facilita o desenvolvimento de um juízo de valor que dificulta a percepção e aceitação, pelos produtores tradicionalmente associados ao campo do design, da complexidade de construção de um projeto que envolva uma coleção de diferentes peças de vestuário. De forma semelhante, a noção que vincula o design à indústria e à racionalidade para direcionar a solução formal de uma necessidade concreta do usuário e das empresas produtoras, dificulta a percepção, pelos produtores de objetos do vestuário vinculados à noção de moda, e até mesmo pelos próprios produtores de objetos tradicionalmente entendidos como de design, da capacidade de expressão autoral e individual dos produtores tradicionalmente vinculados ao campo do design, mesmo percebendo que estas mesmas noções contribuem para formar uma ideia de que o produtor de objetos do vestuário vinculado à noção de moda, formado segundo os critérios e diretrizes dos pensamentos associados ao design, possui uma melhor capacidade de atuação na criação e desenvolvimento do objeto do vestuário.

Além disso, se por um lado parece fácil identificar que a criação e desenvolvimento dos objetos do vestuário vinculados à noção de moda também é uma atividade projetual que se preocupa com as necessidades do consumidor, tanto objetivas e concretas, como subjetivas e abstratas, e também do produtor para desenvolver, segundo uma lógica industrial, as melhores formas para objetos do vestuário, por outro existe uma noção de diferenciação entre um

\footnotetext{
${ }^{5}$ Esta é uma das conclusões apresentadas e defendidas em CHRISTO, Deborah Chagas; CIPINIUK, Alberto. Estrutura e funcionamento do campo de produção de objetos do vestuário no Brasil. Tese (Doutorado) - Pontifícia Universidade Católica do Rio de Janeiro, Departamento de Artes e Design, 2013.
} 
profissional capaz de construir formas inovadoras e únicas por ser livre, autônomo, criativo e detentor de uma expressão própria, normalmente identificado com o produtor de objetos do vestuário nomeado como "estilista", e o profissional capaz de pensar as questões do mercado, da produção, dos custos e dos lucros, normalmente associado ao designer. Além disso, os valores atribuídos para cada uma das posições desta diferenciação se alteram dependendo de quem esteja defendendo cada um destes polos. Desta forma, esta característica atribuída ao designer pode ser entendida como prejudicial em relação às características do "estilista" por limitar e restringir a sua capacidade de criação e expressão, mas também pode ser percebida como estratégica por se preocupar com as demandas dos usuários e das empresas produtoras e não direcionar a sua criação apenas por escolhas individuais. Assim, apesar da clara semelhança entre os processos de criação e desenvolvimento de objetos do vestuário vinculados à noção de moda e de objetos tradicionalmente pertencentes ao campo do design, as noções que permeiam as duas atividades contribuem na dificuldade de aceitação e assimilação da relação entre a produção de objetos de vestuário vinculados à noção de moda e o campo do design, ou seja, apesar de concretamente ser possível identificar a semelhança de estrutura entre um projeto de uma coleção de objetos do vestuário vinculados à noção de moda e um projeto de qualquer outro objeto de design, os valores atribuídos aos conceitos de projeto, usuário, função do objeto e moda em ambos os campos de produção influenciam nos conflitos existentes por conta da aproximação destes dois campos.

\section{A apropriação das noções e valores do campo do design pelas instâncias de reprodução do campo}

Essa dificuldade de aceitação e assimilação pode ser percebida em diferentes instâncias ${ }^{6}$, porém em instituições de reprodução como as escolas responsáveis pela formação de designers de moda, ou mesmo em escolas onde a formação em design inclui a moda como parte das suas habilitações, muitas vezes, isto fica mais explícito, principalmente em disciplinas que tratam dos discursos, técnicas e práticas entendidas como específicos do design, como, por exemplo, as disciplinas que tratam das teorias e práticas específicas de metodologia para o desenvolvimento de projetos de design. Parece difícil transpor para a prática do produtor de objetos de vestuário vinculados à noção de moda, os discursos, técnicas e nomenclaturas vinculadas às noções de projeto, usuário e função que trazem em si valores ideológicos marcados pelo momento específico da constituição do campo do design, mas que ainda influenciam as práticas e noções específicas do campo, e que passaram a fazer parte do currículo das escolas de moda e estilismo quando elas adequaram seus currículos às Diretrizes Curriculares Nacionais do Curso de Graduação em Design. Como adequar, por exemplo, as noções de projeto, usuário e função características do momento da institucionalização do campo do design, carregadas de um conteúdo ideológico de racionalidade, cientificidade e de rejeição às características subjetivas e simbólicas, que ainda influenciam as noções e valores do campo e as práticas dos designers, às práticas de criação e desenvolvimento de objetos entendidos como de moda, ou seja, carregados de conteúdos autorais, subjetivos e simbólicos? Por outro lado, como incluir noções e valores vinculados à noção de moda, ou seja, noções que valorizam o subjetivo, o simbólico e até mesmo autoral, entre

\footnotetext{
${ }^{6}$ Isso pode ser percebido, por exemplo, no VI Fórum de Escolas de Moda, que aconteceu no XVII Colóquio de Moda, em Maringá/PR, em 2011, as escolas de moda do Estado de São Paulo apresentaram documento encaminhado ao MEC solicitando a inclusão de uma área exclusiva para moda, desvinculada da área de design.
} 
produtores onde as noções tradicionais do campo do design ainda são muito marcantes? Como traduzir, por exemplo, a noção de necessidade concreta e objetiva de um usuário para um objeto de moda, ou seja, que utiliza conteúdos simbólicos e subjetivos na sua relação com o indivíduo ou com os grupos sociais para os quais este objeto foi criado, ou seja, que trabalha com necessidades subjetivas e abstratas? Ou como a criação e desenvolvimento de um objeto do vestuário vinculado à noção de moda, onde a escolha por tal objeto se dá, muitas vezes, por questões identitárias a um determinado estilo ou linguagem, pode se adequar a noção do projeto como a solução de um problema específico e concreto do usuário identificado pelo designer? Ou ainda, como lidar com a sazonalidade do produto de moda quando o foco de um projeto de design está na solução de uma necessidade concreta do usuário e não no ciclo de obsolescência imposto pelo movimento do mercado e da indústria? Todas estas questões têm como base as noções e valores que permeiam os campos de produção dos objetos entendidos como de design e dos objetos de vestuário vinculados à noção de moda, ou seja, aparentemente, tudo que mobiliza os movimentos de rejeição e de dificuldade em aceitação da aproximação entre os dois campos parece estar fundamentado em noções e valores imateriais característicos da estrutura e funcionamento de cada campo, porém, gera problemas concretos em diferentes instâncias, como, por exemplo, nas instituições responsáveis pelos processos de ensino das técnicas e práticas de criação, desenvolvimento e produção dos objetos de cada um destes campos.

Algumas escolas que formavam, através de cursos de nível superior, produtores de objetos de vestuário vinculados à noção de moda, ao adequarem seus currículos incluíram, por exemplo, disciplinas específicas de metodologia de projeto de design, aplicando teóricos e bibliografias desenvolvidas para produtos que seguiam as noções de projeto, necessidade do usuário e função do objeto característicos do momento de institucionalização do campo do design, ou, então, incluíam estes conteúdos e suas nomenclaturas e discursos nas disciplinas voltadas para o ensino dos processos de criação e desenvolvimento de produtos de moda ${ }^{7}$. Porém, como, efetivamente, estes conteúdos foram compreendidos, assimilados e transpostos pelos professores e alunos destas instituições?

É interessante observar a preocupação de algumas destas instituições sobre os resultados obtidos em relação às instituições de ensino tradicionais de design nas primeiras provas do ENADE (Exame Nacional de Desempenho de Estudantes), em 2006 e 2009, indicando uma provável dificuldade dos alunos destes cursos em conseguir transpor estes conteúdos tradicionais do campo do design para a criação e desenvolvimento de objetos de vestuário vinculados à moda. ${ }^{8}$

De forma semelhante, é possível perceber o uso de teóricos e bibliografias desenvolvidas para produtos que seguiam as noções de projeto, necessidade do usuário e função do objeto características do momento de institucionalização do campo do design, além de conteúdos,

\footnotetext{
${ }^{7}$ É possível observar a presença de uma disciplina específica para tratar de metodologia de projeto em design, por exemplo, na estrutura dos cursos de Design de Moda da Universidade Veiga de Ameida (Ver em UNIVERSIDADE VEIGA DE ALMEIDA. Disponível em: <https://www.uva.br/sites/default/files/files/ Design_de_Moda__Final_10046742016113.pdf . Acesso em 24 nov 2016) e da Faculdade Senai/Cetiqt (Ver em SENAI. Portal da Indústria. Disponível em: <http://www.portaldaindustria.com.br/senai/iniciativas/ programas/senaicetiqt/educacao/2014/07/1,40899/graduacao-design-enfase-em-moda.html)

${ }^{8}$ Os resultados do ENADE e a estrutura das suas provas para a área de design já foi tema de mesas redondas e de discussões em algumas das edições do Fórum de Escolas de Moda, que acontece regularmente desde 2006 como parte do Colóquio de Moda.
} 
nomenclaturas e discursos relacionados a estas noções em artigos científicos que discutiam a prática do produtor de objetos de vestuário vinculado à noção de moda apresentados em eventos científicos específicos das duas áreas, moda e design, a partir da adequação dos projetos pedagógicos dos cursos de nível superior de estilismo e de moda às Diretrizes Curriculares Nacionais do Curso de Graduação em Design. Porém, a questão ainda é similar, como estes conceitos estavam, e estão, efetivamente, sendo interpretados e utilizados para as práticas relacionadas à criação, desenvolvimento e produção do objeto do vestuário vinculado à noção de moda?

\section{Conclusão provisória}

A análise apresentada neste artigo sobre a influência de noções e valores do campo do design nas práticas e discursos relacionados à criação e desenvolvimento de objetos do vestuário vinculados à noção de moda teve como propósito provocar uma reflexão sobre os conceitos, os discursos, as teorias e as práticas que envolvem a produção de objetos tradicionalmente entendidos como de design e de objetos de vestuário vinculados à noção de moda e, consequentemente, gerar material crítico sobre eles, proporcionando instrumentos que contribuam no estudo de como as noções e valores próprios do campo do design foram apropriados e interpretados pelas instituições de ensino de design e de moda localizadas no Rio de Janeiro, após a adequação, sugerida pelo MEC, dos projetos pedagógicos de cursos de nível superior de moda e estilismo às Diretrizes Curriculares Nacionais do Curso de Graduação em Design, em 2004, e como isso afetou efetivamente as práticas de ensino relacionadas à criação e desenvolvimento do objeto do vestuário vinculado à noção de moda a partir de então, tanto em instituições tradicionais de ensino de design que incluíram a produção de objetos de vestuário vinculados à noção de moda em sua estrutura curricular, como em instituições de ensino de moda e estilismo que fizeram a adequação de seus cursos para cursos superiores de design de moda, e analisar também possíveis diferenças existentes na apropriação destas noções e valores pelos discentes e docentes associados à área de moda nestas diferentes instituições. Para, por fim, avaliar como estas noções e valores vinculados ao campo tradicional do design aparecem efetivamente nas práticas e discursos relacionados à criação e desenvolvimento de objetos de vestuário vinculados à noção de moda.

\section{Referências}

BONADIO, Maria Claudia; MATTOS, Maria de Fátima. (org.) História e Cultura da Moda. São Paulo: Estação das Letras e Cores, 2011.

BONADIO, Maria Claudia. A produção acadêmica sobre moda na pós-graduação stricto sensu no Brasil. In: lara - Revista de Moda, Cultura e Arte - São Paulo - V.3 no 3 dez 2010 - Dossiê - p.50146.

BOURDIEU, Pierre. A distinção: Crítica social do julgamento. Porto Alegre: Zouk, 2007.

A economia das trocas simbólicas. São Paulo: Perspectiva, 1999.

A produção da crença: Contribuição para uma economia dos bens simbólicos. Porto Alegre: Zouk, 2008.

BOURDIEU, Pierre; DELSAUT, Yvette. O costureiro e sua grife: Contribuição para uma teoria da magia. In: BOURDIEU, Pierre. A produção da crença: contribuição para uma economia dos bens 
simbólicos. Porto Alegre: Zouk, 2008. p.113 - p.190.

BOURDIEU, Pierre.; BOLTANSKI, L.; CASTEL Pierre R.; CHAMBOREDON, J.C. Un art moyen, essai sur les usages sociaux de la photographie. Paris: Éd. de Minuit, Le sens commun,1965.

BRAGA João Neto. História da Moda: uma narrativa. São Paulo: Anhembi Morumbi, 2004.

BRAGA, João; PRADO, Luís Andre do Prado. História da moda no Brasil: Das influências às autorreferências. São Paulo: Pyxis Editorial, 2011.

CHRISTO, Deborah Chagas. Designer de Moda ou estilista: reflexões sobre noções e valores do campo da arte, do Design e da Moda In: PIRES, Dorotéia Baduy. Design de Moda: Olhares diversos. São Paulo: Estação das Letras, 2008.

CHRISTO, Deborah Chagas; CIPINIUK, Alberto. O campo do design e consagração das logomarcas: estudo da relação entre as instâncias de legitimação e consagração do campo do design e a linguagem gráfica das logomarcas produzidas nas décadas de 60 e 70 . Dissertação (Mestrado) Pontifícia Universidade Católica do Rio de Janeiro, Departamento de Artes e Design, 2003.

CHRISTO, Deborah Chagas; CIPINIUK, Alberto. Estrutura e funcionamento do campo de produção de objetos do vestuário no Brasil. Tese (Doutorado) - Pontifícia Universidade Católica do Rio de Janeiro, Departamento de Artes e Design, 2013.

CHRISTO, Deborah Chagas. Estrutura e funcionamento do campo de produção de objetos do vestuário no Brasil. São Paulo: Ed. Das Letras e Cores, 2016.

PIRES, Dorotéia Baduy. Design de Moda: Olhares diversos. São Paulo: Estação das Letras, 2008.

. Design de moda: uma nova cultura. In: DOBRAS, Revista. São Paulo: Editora Estação das Letras, v.1, n.1, outubro 2007. p. 66-73.

A história dos cursos de design de moda no Brasil. In: REVISTA NEXOS: Estudos em Comunicação e Educação. Especial Moda/Universidade Anhembi Morumbi - Ano VI, no 9 (2002) São Paulo: Editora Anhembi Morumbi, 112 p. ISNN 1415-3610.

SABRÁ, Flávio Glória Caminada; CIPINIUK, Alberto. Os agentes sociais envolvidos no processo criativo no desenvolvimento de produtos da Cadeia Têxtil. Tese (Doutorado) - Pontifícia Universidade Católica do Rio de Janeiro, Departamento de Artes e Design, 2015.

SABRÁ, Flávio Glória Caminada. Os agentes sociais envolvidos no processo criativo no desenvolvimento de produtos da Cadeia Têxtil. São Paulo: Ed. Das Letras e Cores, 2016.

WOLFF, Janet. A produção social da arte. Rio de Janeiro: Zahar, 1982.

\section{SITES}

ABIT. Perfil do Setor: Dados gerais do setor atualizados em 2016, referentes ao ano de 2015. Disponível em: < http://www.abit.org.br/cont/perfil-do-setor. Acesso em 28 nov 2016

DIRETRIZES CURRICULARES PARA CURSOS DE GRADUAÇÃO EM DESIGN. Disponível em: <http://portal.mec.gov.br/cne/arquivos/pdf/rces05_04.pdf>. Acesso em: 29 nov. 2016.

FACULDADE SENAI/CETIQT. Disponível em: <http://www.portaldaindustria.com.br/ senai/iniciativas/programas/senai-cetiqt/educacao/2014/07/1,40899/graduacao-design-enfase- 
em-moda.html>. Acesso em: 29 nov. 2016.

INEP. Disponível em: http://emec.mec.gov.br/emec/consulta-cadastro/detalhamento/ d96957f455f6405d14c6542552b0f6eb/MTY1/9f1aa921d96ca1df24a34474cc171f61/NzU=>. Acesso em 20 nov. 2016.

MEC. Disponível em <http://mec.gov.br>. Acesso em 29 nov. 2016.

PONTIFÍCIA UNIVERSIDADE CATÓLICA DO RIO DE JANEIRO. Disponível em: <www.puc-rio.br>. Acesso em: 29 nov. 2016.

UNIVERSIDADE VEIGA DE ALMEIDA. Disponível em: <https://www.uva.br/ sites/default/files/files/Design_de_Moda_-_Final_10046742016113.pdf>. Acesso em 24 nov. 2016. 